\title{
Publicaciones especializadas y liberalismo periférico. Notas sobre la transmisión de ideas económicas en Argentina, 1870-1890
}

\author{
por \\ Mariano Ben Plotkin \\ Jimena Caravaca \\ IDES/CONICET-Universidad Nacional de Tres de Febrero \\ IDES/CONICET
}

Este artículo — parte de un proyecto mayor sobre la conformación de «saberes de Estado» en la Argentina entre finales del siglo XIX y 1930 - se plantea como objetivo analizar una serie de publicaciones que operaron como «correas de transmisión» de saber económico y, en términos más generales, de concepciones vinculadas al liberalismo durante las últimas décadas del siglo XIX. Lo que pretendemos reconstruir es el doble proceso a partir del cual el saber sobre la economía da lugar a un «discurso experto» reconocido socialmente como tal y, al mismo tiempo, ciertas ideas vinculadas a la economía y a la sociedad llegaron a conformar lo que podría definirse como un -siempre cambiante- «sentido común social».

Palabras Clave: Economía; Saberes de Estado; Argentina; Periódicos.

Este trabajo se inserta en un proyecto mayor que explora la articulación entre la conformación de «saberes de Estado» — en particular la economía-, la modernización del Estado, la circulación transnacional de ideas y los momentos definidos socialmente como críticos en la Argentina ${ }^{1}$. El objetivo que

\footnotetext{
${ }^{1}$ Este artículo es uno de los resultados del Proyecto de Investigación «Circulación internacional de saberes y prácticas institucionales en la consolidación del Estado Social en Argentina». HAR 2009-13555, financiado por el programa I+D del Ministerio de Economía y Competitividad del gobierno de España.
} 
nos planteamos en este artículo es analizar una serie de publicaciones que operaron como «correas de transmisión» de saber económico $\mathrm{y}$, en términos más generales, de concepciones vinculadas al liberalismo durante las últimas décadas del siglo XIX. Lo que pretendemos reconstruir parcialmente, a partir de este y otros trabajos, es el doble proceso a partir del cual el saber sobre la economía da lugar a un «discurso experto» reconocido socialmente como tal $\mathrm{y}$, al mismo tiempo, ciertas ideas vinculadas a la economía y a la sociedad llegaron a conformar lo que podría definirse como un - siempre cambiante«sentido común social». Por «sentido común social» entendemos la forma en que ciertos sistemas de ideas y de creencias trascienden los ámbitos académicos $\mathrm{y}$, en general, aquellos vinculados a la «alta cultura» para conformar aquella porción de la realidad que Peter Berger definió como «el mundo como dado», es decir lo que está más allá de cuestionamientos inmediatos.

En un trabajo anterior focalizamos en la difusión de ideas sobre economía en el mundo académico ${ }^{2}$. En este texto, que puede ser leído como complementario al anterior, comenzamos a mapear circuitos de recepción y circulación de ideas económicas y sociales que pasaban por fuera de los «grandes periódicos» y los «grandes pensadores». Nos centraremos en tres publicaciones cuyo interés reside no solamente en los grupos a los que representan, sino en el hecho de que podrían ser descritas como «heterodoxas» en lo que se refiere a sus posturas respecto del debate proteccionismo-librecambio, de la política económica en general y de la definición de las responsabilidades que atribuían al Estado. Los periódicos son: El Industrial, publicado por el Club Industrial creado en 1875; El Economista, publicado a partir de 1877, y la Revista Económica del Río de la Plata (RERP) que tuvo dos épocas: la primera - muy breve - a principios de los 70, y una posterior mucho más extensa que comienza en 1892.

Estas tres publicaciones respondían a intereses particulares y formaban parte de una constelación de «publicaciones especializadas» existente desde las últimas décadas del siglo XIX en la Argentina. Estos periódicos, además, conformaban un verdadero espacio de sociabilidad en el que se establecían diálogos y debates, se traducían y reproducían textos extranjeros, y desde donde se interpelaba al Estado. En este sentido, formaban parte de una incipiente aunque muy activa «esfera pública», es decir, núcleos de presión, crítica y diálogo con los poderes públicos. Así, por ejemplo, en abril de 1876, representantes de 16 diarios y periódicos de todas las tendencias se pusieron de acuerdo (más por consenso que por unanimidad, y a pesar de las críticas puntuales de algunos de ellos) para proponer un proyecto de ley provincial sobre cédulas hipoteca-

\footnotetext{
2 Plotkin y Caravaca, en prensa.
} 
rias y enajenación de obras de salubridad. Entre los periódicos participantes estaban los «grandes», como La Nación, pero también los «pequeños», como El Industrial, que sostenían posiciones opuestas sobre muchos temas.

En general, la historiografía ha prestado atención a los «grandes periódicos» o a la prensa partidaria en los análisis de conformación de una esfera pública a partir de la segunda mitad del siglo XIX ${ }^{3}$. Sin embargo, la existencia de «pequeños periódicos» de frecuencia semanal o quincenal, que respondía a intereses corporativos, profesionales o técnicos, con diverso nivel de sofisticación doctrinaria, también constituyó un elemento importante de debate e intervención en la cosa pública, y sobre algunos de ellos nos detendremos en este trabajo. Estos periódicos se definían a sí mismos por estar ubicados fuera (y en oposición) de la política partidaria. Cada uno de ellos decía defender posiciones «concretas»y «realistas» para el bien del país frente a la prensa partidaria y a la política en general. Todos ellos participaban — cada uno a su manera- del «consenso liberal» que se estableció en el país durante la segunda mitad del siglo XIX, pero a su vez introducían en él importantes matices que dan cuenta de patrones particulares de recepción de las ideas liberales en Argentina y América Latina durante el siglo XIX. Nos centraremos en un período particular delimitado por dos crisis: la ocurrida en la década de 1870 y la de 1890, partiendo de la hipótesis de que las crisis constituyen «momentos fuertes» en el proceso de construcción y consolidación de los saberes de Estado, que abrirían las puertas para cambiar el universo de lo decible permitiendo cambios de paradigmas.

\section{EL INDUSTRIAL Y LOS INDUSTRIALES}

El Club Industrial fue fundado en 1875 por un grupo de industriales y, sobre todo, artesanos — la mayoría de ellos de origen europeo-, jefes de empresas de diversa magnitud. Además de los socios directamente vinculados a la producción, el Club nombró como socios honorarios a figuras públicas que apoyaban la causa industrialista, tales como Vicente Fidel López, Miguel Cané y Carlos Pellegrini. Desde el principio, la asociación reclamaba para sí un rol como interlocutor del Estado. A pesar de las quejas constantes de los «industriales» sobre la poca atención que les prestaban los poderes públicos, lo cierto es que entre los miembros activos del Club es posible encontrar funcionarios, diputados, senadores e incluso algún ministro, lo cual le reportaba beneficios. Así, por ejemplo, en 1878 el diputado provincial Enrique Moreno (socio honorario

\footnotetext{
${ }^{3}$ Alonso, 2000; 2010. Sidicaro, 1993. Tato, 2004.
} 
del Club) consiguió que la Cámara de Diputados de la provincia votara una subvención mensual de 5000 pesos moneda corriente para la institución, similar a la que venían recibiendo otras instituciones corporativas y de interés general tales como la Sociedad Científica Argentina ${ }^{4}$. El propio presidente Nicolás Avellaneda participó en más de una actividad organizada por el Club, inaugurando el ciclo de conferencias que se abrió en agosto de $1879^{5}$. En las celebraciones de la asociación, aparte del presidente, participaban rutinariamente los ministros de Hacienda de la Nación y de la Provincia de Buenos Aires, entre otros altos funcionarios. Por otro lado, al igual que otras organizaciones corporativas, el Club Industrial era consultado habitualmente por las autoridades para la formulación de legislación que afectara los intereses industriales, incluyendo, desde luego, las leyes de aduana y tarifas de avalúo. A partir de la sanción de la Ley de Patentes en 1876, el Club actuaba como jury para determinar el cobro de patentes a los industriales o su exoneración, según el tipo de materia prima utilizada y las características de los distintos establecimientos ${ }^{6}$.

Desde su creación, el Club editó de manera quincenal El Industrial, una publicación que se repartía en forma gratuita entre sus socios. Allí pueden verse algunas de las líneas ideológicas sostenidas por la institución. Como podría esperarse, en el debate entre proteccionismo y libre cambio, El Industrial adhería al proteccionismo. Sin embargo, esta adhesión, al igual que la de políticos e intelectuales con los que compartía el punto de vista, estaba fuertemente matizada: el periódico se veía obligado a defenderse constantemente de los cargos de ser proteccionista que le formulaban otros medios de prensa más ortodoxos. Así, en el primer número de la publicación, se puede leer: «No pertenecemos a ninguna escuela; no somos librecambistas ni proteccionistas sino industriales, e industriales establecidos en la República Argentina», aunque unas líneas más abajo puntualizaba: «Deseamos el libre cambio entre la República Argentina y todas las demás naciones, pero exigimos que se equilibre nuestro libre cambio. [...] Libre cambistas

${ }^{4}$ De manera semejante, en 1877 el Senador Provincial Manuel Gache, también socio honorario del Club, presentó un proyecto para la creación de una oficina dentro del Banco de la Provincia que estaría dedicada a otorgar crédito a industriales y artesanos. Hacia 1877 el Club declaraba tener más de trecientos socios activos.

${ }_{5}^{5}$ De la misma manera, cuando el Centro Industrial se escinde del Club Industrial, será el expresidente Nicolás Avellaneda quien convoque, desde 1881, a sesiones para crear una asociación única que representara los intereses industriales. Esto sucederá recién en 1887 con la creación de la Unión Industrial Argentina.

${ }^{6}$ Ver, por ejemplo, El Industrial, 5/156 (13 de diciembre de 1879). Esto da cuenta no solo de lo extendido a nivel territorial de la asociación, sino también, como contrapartida, de las dificultades del Estado Nacional para llevar adelante un control sobre todo el territorio nacional. 
en principio, llegamos a ser imperiosamente proteccionistas ${ }^{7}$. A pesar de solicitar constantemente medidas proteccionistas de distinta índole, pocas veces El Industrial se declaraba abiertamente proteccionista: «El libre-cambio absoluto es el desiderátum, es el ideal que persigue todo pueblo que aspira a llegar a la cima del progreso, sobre cuya cúspide está escrito con caracteres indelebles el lema santo ¡libertad! [...] Libertad piden los pueblos, libertad pide el comercio, libertad pide la industria, libertad pide el pensamiento. [...] Libertad sin reticencias, libertad absoluta». Pero inmediatamente esta idea de libertad aplicada al comercio exterior se matizaba ya que «[...] para cubrir estos déficits necesitamos producir transformando nuestras materias primas y para transformar las materias primas tenemos forzosamente que establecer la industria», para lo cual se reclaman con urgencia medidas proteccionistas ${ }^{8}$. El proteccionismo era visto como un conjunto de medidas particulares que no podían entrar en colisión con un conjunto de ideas asociadas al liberalismo en términos más generales.

En algunas oportunidades, el Club también proponía medidas librecambistas, por ejemplo, al oponerse a la protección del azúcar, que constituía una materia prima básica para la confección de dulces, o al proponer en 1877 la liberación de la entrada de trigo por un lapso de 23 meses a efectos de evitar la suba del precio, lo que perjudicaba a los sectores populares, pero sin duda también a aquellas industrias que dependían del trigo como materia prima. A efectos de justificar estas medidas, El Industrial recurría a citas canónicas de los padres fundadores del liberalismo económico, tales como Adam Smith y Frédéric Bastiat ${ }^{9}$. Pero por otro lado, y de manera sistemática, aparecían citados otros autores vinculados al proteccionismo, en particular el alemán Friedrich List y el norteamericano Henry Carey, autores que no formaban parte del canon académico. Al respecto decía El Industrial:

La Escuela de Manchester ha creado un poderoso núcleo de Doctores, cuyo único programa es la fabricación de teorías con destino al estrangero (sic); y estos Doctores trabajan sin descanso la mercancía de contrabando intelectual, así como sus comitentes tejidos de algodón con que abarrotar los mercados del universo ${ }^{10}$.

Frente a este «contrabando intelectual», se quejaba El Industrial: «¡No se estudian los libros de List, Carey, Blunschli y otros independizadores económicos de sus respectivas nacionales, pero se aceptan las esclavizadoras

\footnotetext{
${ }^{7}$ El Industrial, 1/ 1 (1 de octubre de 1875): 1.

8 P. Y., El Industrial, III/104 (2 de diciembre de 1878).

${ }^{9}$ El Industrial, III/45 (2 de agosto de 1877): 393.

10 J. L. L., El Industrial, V/195 (30 de octubre de 1880): 1-2.
} 
teorías de Adam Smith, Herbert Spencer y otros semejantes acólitos del Secret service Money» ${ }^{11}$.

En realidad, el universo de citas introducido por El Industrial tenía un gran nivel de heterogeneidad, ya que incluía, como se vio, a algunas figuras clave del pensamiento económico ortodoxo y no tanto, junto con otros menos esperables tales como Pierre-Joseph Prudhon y Auguste Blanqui (a quien caracterizaban de librecambista, ya que probablemente lo confundían con su hermano, el economista librecambista y sucesor de J. B. Say, Jérôme-Adolphe Blanqui).

Al igual que otros periódicos, El Industrial constituía un espacio de recepción y circulación de ideas y autores. Y al igual que otros espacios, la recepción que se realizaba no era pasiva, sino creativa y altamente selectiva. Así, por ejemplo, se citaba profusamente a List como una autoridad reconocida para validar las pretensiones industrialistas. Los industriales se hacían eco de las ideas listeanas sobre las infant industries como forma de lograr el desarrollo de las potencialidades de cada economía. La doctrina sobre las industrias incipientes remite a la noción según la cual los países atraviesan cuatro etapas productivas de creciente desarrollo (vida pastoril; agricultura; agricultura y manufactura; y la conjunción de la agricultura, la manufactura y el comercio como etapa superior). Sería misión del Estado guiar el camino hacia la consecución de esa evolución del sistema productivo que ubicaba en la manufactura el máximo escalafón en el camino hacia la independencia económica.

Sin embargo, la apropiación de las ideas de List por parte de los industriales argentinos era selectiva. Es sabido que el alemán tenía ciertas prevenciones frente a la posibilidad de que países como la Argentina pudieran generar una industria propia. En efecto, List había dividido en sus escritos el mundo en dos mitades: una templada y otra tropical. La prescripción de un Estado activo en la protección industrial para el desarrollo de los poderes productivos se aplicaba, en su teoría, solamente a los países de clima templado. Los otros, entre los que se incluía la Argentina junto con Chile y Uruguay, pertenecían, según la peculiar geografía de este autor, a la zona tropical, cuyo clima le daba la ventaja de una producción agrícola monopólica, como contrapartida de la producción industrial de las naciones templadas. El intercambio entre ambos tipos de países era concebido por el alemán como complementario e interdependiente. Los países «tropicales», en su concepción, no debían buscar ni proteger la industrialización, ya que los consideraba «incompatibles» con la producción industrial ${ }^{12}$.

11 J. L. L, El Industrial, V/226 (4 de junio de 1881): 1-2.

12 Boianovsky, 45/4 (abril 2011): 12. 
Más curiosa fue la utilización que El Industrial hacía de autores francamente librecambistas, como el inglés Henry Dunn Macleod (muy citado en la época, aunque poco leído) para justificar posiciones contrarias. Así, en una respuesta a un artículo aparecido en el diario La Nación en el que se acusaba al órgano del Club Industrial de proteccionista fanático, El Industrial introducía al autor inglés:

Ahora dejemos la palabra a Macleod, el economista más distinguido de estos últimos tiempos. Oídle. «El único caso en que es posible defender los derechos protectores es aquel en que se establecen temporariamente, con especialidad en un país joven y progresista, para naturalizar industrias extranjeras que se adapten perfectamente a la situación del país ${ }^{13}$.

La cita atribuida a Macleod en realidad no le pertenecía, sino que era de John Stuart Mill, y había sido introducida por Henri Richelot, un funcionario francés que había escrito un libro sobre Macleod consistente en una traducción comentada de algunos de sus textos. El libro de Richelot fue traducido al español y constituyó una vía de entrada privilegiada del pensamiento de Macleod en la Argentina, al punto tal que el propio Vicente Fidel López, siendo profesor de Economía Política en la Facultad de Derecho de la Universidad de Buenos Aires, cometió exactamente el mismo «error» —-más bien lapsus—, al intentar utilizar a Macleod para sostener sus puntos de vista proteccionistas ${ }^{14}$.

El marco ideológico donde se movían los industriales y que se manifestaba en las columnas de El Industrial era complejo, no tanto por su sofisticación teórica (que rara vez se ponía de manifiesto), sino por sus múltiples y heterogéneas fuentes. Los fundamentos del liberalismo conformaban sin duda el marco de referencia obligado, dentro de un consenso que lo constituía como parte del «mundo como dado». Así, es posible encontrar elementos del socialismo utópico de origen saint-simoniano en la idea muchas veces sostenida de que debería ser en los industriales, y no en los abogados, en quienes debía recaer la responsabilidad de la conducción de la cosa públi$\mathrm{ca}^{15}$; así como en una concepción de la sociedad en la que los intereses de proletarios e industriales, lejos de estar en disputa, serían idénticos ${ }^{16}$. En

13 El Industrial, III/50 (15 de octubre de 1877).

${ }_{14}$ Plotkin y Caravaca, en prensa; Plotkin y Caravaca, 21/2 (San Pablo, 2009).

15 La campaña contra los abogados era una constante en El Industrial, y se completaba con el reclamo, igualmente firme, por escuelas de artes y oficios, de que educaran una nueva generación de obreros calificados para la labor industrial, como contracara de los abogados a los que consideraban «zánganos de la colmena del Estado». Ver J.L.L., El Industrial, 5/185 (17 de julio de 1880): 2.

${ }^{16}$ La recepción del socialismo utópico en la Argentina no se originó en los industriales. Ya en la década de 1850 se puede rastrear elementos de esta forma de pensamiento en las 
realidad los industriales se identifican a sí mismos como trabajadores. Frente a un artículo titulado «La Internacional, publicado por El Correo Español, El Industrial respondía:

¿Cree el colega que solamente él conoce las necesidades del obrero? No, el industrial, mejor que nadie, conoce la difícil situación de los hijos del trabajo. Sí, solamente los industriales establecidos somos capaces de comprender lo que es miseria. [...] Desengáñese, colega, los intereses de industriales y obreros se encuentran completamente ligados ${ }^{17}$.

En otra oportunidad, un miembro destacado del club, historiando sus orígenes, decía:

Fue a fines de 1875, cuando unos obreros, convencidos de que la República Argentina podía presentarse y tomar su puesto entre las naciones fabriles fundaron en Club Industrial ${ }^{18}$.

En el sistema de «inclusión y exclusión construido por los industriales, el «enemigo de clase no era el obrero, sino el comerciante importador. Así, en 1878 el Club presentó su propia propuesta de ley de aduanas donde proponía una fuerte protección para los productos que se produjeran en el país, así como una política muy liberal para el ingreso de materias primas y maquinarias. Hay aquí una clara definición de la incompatibilidad de intereses entre comerciantes e industriales que se ponía de manifiesto también desde las páginas de El Industrial:

De parte del primero [el comercio] están los utopistas, los adeptos a las teorías liberales, al monopolio y al numerario. De parte del segundo [la industria], el proletariado, los hombres prácticos, aleccionados por la experiencia, las fuentes naturales de producción y la riqueza futura del país en expectativa. Este grandioso debate no es más, pues, que la lucha del capital con el trabajo ${ }^{19}$.

Esta «lucha del capital con el trabajo» no era conceptualizada como una auténtica lucha de clases ya que, en realidad, se trataba del combate por los intereses encontrados entre comercio e industria. La lucha entre el capital y el trabajo no podía tener lugar dentro del ámbito fabril, ya que los propios industriales se identificaban con el mundo del trabajo.

ideas de Mariano Fragueiro. Ver Fragueiro, 1976. Ver en particular el «Estudio Preliminar» a cargo de Gregorio Weinberg.

${ }_{17}$ El Industrial, I/3 (1 de noviembre de 1875): 23.

${ }^{18}$ El Industrial, III/ 33 (1 de febrero de 1877): 264. El propio Presidente Avellaneda, en su discurso de inauguración de la Exposición Industrial, se refería al Club como aquel que «representa legítimamente las clases laboriosas de Buenos Aires».

${ }_{19}$ Club Industrial, 1878. 
Sin embargo, esta construcción identitaria de los industriales tenía importantes matices. Para empezar, pronto se hizo claro que la fuerte presencia de comerciantes dentro del Club Industrial — basta ver la publicidad que $E l$ Industrial publicaba desde sus orígenes que incluía casas importadoras de ropa y dulces al lado de fabricantes de máquinas agrícolas-, forzó necesariamente a una relación de colaboración entre ambos sectores. Desde las páginas de El Industrial, gradual pero rápidamente se exalta la importancia de la colaboración entre los dos sectores, aun para cuestiones tan álgidas como las leyes de aduanas. Así, en 1880, el periódico informa que «El Club Industrial y el Centro Comercial están de parabienes», ya que representantes de ambas asociaciones habían trabajado en conjunto y en colaboración con la Dirección de Rentas para fijar las tarifas de avalúo. El Industrial expresaba sus esperanzas de que «la prosecución de estos trabajos han de unir más y más entre sí al comercio y la industria, dejando a un lado como traste viejo las preocupaciones de antaño que nunca tuvieron razón de ser» ${ }^{20}$.

Estas tensiones sobre la identidad de los miembros de los círculos industriales sobrevivirían a la conformación de la Unión Industrial Argentina (UIA) en 1887. En septiembre de 1890, una nota comentaba el malestar que había provocado entre muchos miembros el hecho de notar que en la lista de asociados había introductores, a los que consideraban «incompatibles con el título de socio de nuestra sociedad». El firmante de la nota sostenía, sin embargo, que todos los industriales eran en parte introductores, ya que necesitaban abastecerse de materiales de origen externo, y que los socios definidos como introductores eran también canales de venta para la producción local en el mercado interno, ya que en tanto vendedores vendían lo que fuera, sin importar el origen ${ }^{21}$.

También la identificación entre industriales y trabajadores se volvía problemática cuando comenzaron a aparecer los primeros atisbos de lo que se llamaría la «cuestión social». Así, por ejemplo, cuando en una asamblea de 1876 un socio propuso aceptar como socios del club a los operarios, Policarpo Yurrebaso, gerente-secretario del Club, se opuso terminantemente a la idea, temiendo que «aceptando al temperamento propuesto, se confundiera la Sociedad con alguna de las conocidas por asociaciones socialistas ${ }^{22}$. De la misma manera, cuando en 1879 los cigarreros se declararon en huelga, El Industrial mostró su oposición, pero también sus ambigüedades. «Hemos sido obreros y pasado en los talleres más de veinte años de nuestra vida», diría el

\footnotetext{
${ }^{20}$ El Industrial, V/156 (13 de diciembre de 1879).

${ }^{21}$ G. D., Boletín de la UIA, II/180 (18 de Septiembre de 1890).

${ }^{22}$ El Industrial, II/ 30, (15 de diciembre de 1876): 243.
} 
mismo Yurrebaso y, por eso, «nos creemos con algún derecho para salir en su defensa siempre que reclame justicia, como hemos de condenarle cuando como hoy se lanza a la calle con pretensiones absurdas ${ }^{23}$. Frente a la idea de los cigarreros de formar cooperativas de producción (que perjudicarían a los industriales), El Industrial proponía, en cambio, la formación de cooperativas de consumo.

En 1877 se produjo una escisión en el Club Industrial. El Centro Industrial nació a partir de la renuncia de un grupo de socios del Club Industrial debido a lo que consideraban excesos en el celo proteccionista del Club, pero también a problemas internos ${ }^{24}$. Si bien el Centro inició su publicación, $L a$ Industria, marcando diferencias con el Club, con el correr de los años las posturas se acercaron bastante hasta converger en la creación, en 1887, de la Unión Industrial Argentina, a instancias del Poder Ejecutivo Nacional.

\section{EL ECONOMISTA Y LOS FUNCIONARIOS ESTATALES}

El Economista era un periódico quincenal que comenzó a salir en 1877 dirigido por Ricardo Napp, funcionario del Ministerio de Hacienda y tipógrafo miembro del Club Industrial, igual que otro de los articulistas más importantes: Ignacio Firmat. En la publicación también participaban — sobre todo en el comienzo - intelectuales/técnicos como el ingeniero alemán G. Avé Lallemant, quien ocuparía un lugar importante la recepción del marxismo en Argentina ${ }^{25}$.

Vale la pena detenerse en El Economista por dos motivos: en primer lugar, porque parece haber representado los intereses de una elite técnica estatal en formación. Buena parte de sus colaboradores, incluyendo a Francisco Latzina, Melchor Rom, el propio Napp y otros formaban parte de la incipiente burocracia técnica que demandaba abiertamente para sí un lugar más prominente en la producción y análisis de estadísticas y datos en general, con buenos salarios y protección social. Siguiendo en cierta medida ideas propuestas por François Guizot en Francia, El Economista sostenía que los funcionarios rentados debían tener injerencia en el Congreso Nacional, ya que la disposición constitucional que lo prohibía «priva al Congreso de miembros bien interiorizados en ciertos

\footnotetext{
${ }^{23}$ P. Y., El Industrial, V/139 (6 de agosto de 1879): 1190.

${ }^{24}$ El Industrial, V/161 (17 de enero de 1880): 1-2.

25 Tarcus, 2007: capítulo III.
} 
asuntos administrativos sobre los que tiene que legislar sin tener más datos que los que el P. E. juzgue conveniente proporcionar» ${ }^{26}$.

Esta identidad emergente como funcionarios del Estado da cuenta de un incipiente proceso de modernización estatal. En algunos casos esta identidad entraba en colisión con otra más asociada a intereses de clase, y esto se manifestaba en conflictos ocurridos dentro de las organizaciones corporativas. Así, en 1881, al momento de publicarse la Estadística Comercial oficial que contaba con un informe preliminar de Ricardo Napp, el Centro Industrial sostenía que «habríamos deseado que al mandar ese libro a publicidad, se hubieran arrancado de él esas diez páginas que parecen escritas para vergüenza de nuestros gobiernos. [...] son una MENTIRA TIPOGRÁFICA, un sarcasmo de estadística, el empirismo de los números llevado a los más altas regiones de la Administración Nacional» ${ }^{27}$. El informe elaborado por Napp podía responder a necesidades públicas, pero no necesariamente a las necesidades de la corporación a la que el mismo Napp pertenecía. La gradual separación entre los intereses públicos y los sectoriales podría ser explorada como una de las características centrales de la lenta conformación de una burocracia profesional y moderna.

Las relaciones entre el periódico y el Estado iban más allá de la presencia de funcionarios entre los colaboradores. La publicación tenía un convenio con el gobierno nacional por el cual recibía una subvención a cambio de publicar estadísticas de interés público, tales como el movimiento mensual de aduanas, y por eso fue acusada de oficialista por otros medios ${ }^{28}$. El hecho de que el gobierno encargara a una publicación privada la publicación de estadísticas de gran importancia refleja en buena medida la debilidad del aparato técnico-burocrático oficial.

Desde un principio el periódico se insertaba en el debate entre proteccionistas y librecambistas. En ese sentido, se puede ver, al igual que en el caso de $E l$ Industrial y otros, que la posibilidad de declararse abiertamente proteccionista estaba aún fuera de las condiciones de posibilidad de lo abiertamente decible. Aunque a lo largo de su vida El Economista estuvo cerca de los intereses representados por el Club Industrial, al igual que este y que intelectuales y académicos que compartían el punto de vista, las referencias al proteccionismo estaban fuertemente matizadas. En el programa presentado en su primer

${ }^{26}$ El Economista, I/I/12 (15 de junio de 1877): 250. Sobre las ideas de Guizot al respecto, ver Rosanvallon, 1985: 53.

${ }^{27}$ I. F., La Industria, II/37 (31 de octubre de 1880): 311-312. Mayúsculas en el original.

28 Aunque El Economista negaba sistemáticamente esta acusación, el hecho es que se ve claramente una fuerte alineación con las políticas del gobierno federal, y en particular con las ideas y medidas tomadas por el ministro de Hacienda Victorino de la Plaza, en contra de las políticas llevadas a cabo por la provincia de Buenos Aires y en particular su ministro de Hacienda Francisco Balbín. 
número, la publicación se autoproclamaba ecléctica, es decir «no principista», en materia del debate entre librecambistas y proteccionistas, «dejándose guiar única y exclusivamente por las necesidades y conveniencias del país que, según las circunstancias, podrán exigir en esta época, o para esta materia la adopción más o menos absoluta de medidas decididamente proteccionistas, mientras que, a poco de andar, será quizá preferible apoyarse en el sistema contrario ${ }^{29}$. Si el país no podía ser librecambista todavía — es decir, llegar al desiderátum-, esto se debía fundamentalmente a cuestiones prácticas: las únicas rentas con que contaba el gobierno eran las rentas de aduana.

Aunque algunos articulistas del periódico se hacían eco de aquellos grupos que sostenían que el país no estaba aun en condiciones de desarrollar una industria que no fuera la ganadera, la línea general del periódico, expresada en sus editoriales, coincidía con los argumentos de la infant industry de List (aunque este autor raramente aparecía mencionado) que sostenía El Industrial. Otro de los argumentos esgrimidos desde las columnas de El Economista en favor de la industrialización se basaba en la existencia de un diferencial de ingreso entre la industria y las actividades agrarias. Según un artículo del economista francés Jules Du Mesnil-Marigny intitulado «Estudio Estadístico sobre el comercio en general» y publicado en El Economista, el intercambio entre naciones industriales y naciones agrícolas sería por naturaleza desigual. Las naciones industriales tendrían mayores ingresos que las agrícolas. Los obreros que intervienen en la industria ganarían cerca del cuádruple que los que intervienen en agricultura ${ }^{30}$.

Tanto El Economista como El Industrial proclamaban la necesidad de que el Estado se independizara de las rentas de aduana, prácticamente la única fuente de ingreso cierta en ese momento, ya que recién entonces podría plantearse la posibilidad de llevar a cabo una política industrial y comercial autónoma ${ }^{31}$. Es interesante destacar que uno de los argumentos fundamentales en los que se basaba la prédica industrialista $-\mathrm{y}$ por ende proteccionista - de ambas publicaciones era la necesidad de lograr «independencia económica» respecto de Europa, lo que había quedado trunco luego de haberse logrado la independencia política ${ }^{32}$. Frente al ejemplo de los EE.UU. que habían logrado

29 El Economista, $1 / 1$ (18 de enero de 1877). Subrayado en el original.

30 El Economista, V/III/17 (1 de mayo de 1879).

${ }^{31}$ Este era el punto de vista opuesto al mantenido por Bartolomé Mitre, quien rechazaba cualquier tipo de proteccionismo y para quien la única justificación de la existencia de la aduana era como fuente de ingresos físcales.

${ }^{32}$ En marzo de 1876, por ejemplo, El Industrial reprodujo una nota aparecida en el periódico El Nacional, donde se sostenía: «La Europa sonriendo ante nuestras veleidades de hombres libres, ante nuestra altivez americana nos observa, nos dirige, nos domina, como nos 
colocar los papeles de su deuda en el mercado interno a efectos de evitar la dependencia con el extranjero, la dependencia argentina respecto de Gran Bretaña era considerada total ${ }^{33}$. Para contraponerse a la influencia europea, y al igual que El Industrial, desde las páginas de El Economista también se proponía la creación de un Zollverein latinoamericano, poniendo nuevamente de manifiesto el vínculo con la obra de List.

El «eclecticismo» proclamado por El Economista también se refería a temas más generales. El Estado tenía que cumplir un papel importante en las iniciativas de desarrollo económico y social, pero esto era un mal que debía solucionarse con el tiempo: «En el estado en que aún se halla la República, la iniciativa de casi todos los adelantos debe partir de su gobierno. Es este un mal de gravedad, pero existe y por consiguiente debemos aceptarlo, si bien con la firme decisión de combatirlo prudentemente», se decía también en la editorial del primer número ${ }^{34}$. Más adelante, Melchor Rom, admitía:

Loable es sin duda su empeño [del gobierno] cuando, usando de facultades que le son propias y en posesión de los necesarios elementos, trata de difundir la enseñanza, de conquistar para el cristianismo y para la civilización a las tribus salvajes, por medio de misiones religiosas; de contribuir a conservar la moral y buenas costumbres, por los que la Constitución pone en sus manos [los fondos adecuados] [...]; de mejorar y aumentar la viabilidad, haciendo fáciles las comunicaciones y el cambio de los productos; de infundir el deseo de saber y despertar el espíritu de empresa...; de propender al aumento de la población, incitando, por medio de agentes estipendiados, a que las clases laboriosas de la Europa emigren a nuestro feraz suelo; de propender al desarrollo de la agricultura, formando escuelas o colonias con ese objeto.

Sin embargo nada de esto constituía, en la visión de Rom, la esencia de un gobierno republicano, democrático y federal. Por el contrario, el mejor gobierno, sostenía Rom, era el que gobernara menos ${ }^{35}$. Pero por otro lado, El Economista proponía medidas francamente intervencionistas, tales como estatizar la Bolsa de Comercio o, si esto no fuera posible, asegurarse de que la misma operara en un edificio público a efectos de que el gobierno pudiera

dirigirá, absorberá y dominará mientras nos vista, nos calce, nos provea de todos los artículos que son indispensables para la vida». El Industrial, II/11 (1 de marzo de 1876): 86.

${ }^{33}$ El Economista, III/ II/ 6 (8 de febrero de 1878).

${ }^{34}$ Desde las páginas de El Industrial también es posible percibir una tensión respecto de este punto. Mientras se proclamaba por un lado la necesidad de que la iniciativa parta del sector privado, a cada instante exigían al Estado políticas activas en materia económica y, por supuesto, protección para el sector que representaban. Estas demandas se ven con claridad durante el período alrededor de la crisis de 1874-5.

${ }^{35}$ El Economista, I/I/3 (15 de febrero de 1877). 
ejercer un control mayor sobre la misma ${ }^{36}$, mientras en otras instancias se demandaba un gobierno activista y fuerte. "Queremos un Gobierno fuerte - no contra, sino con, por y para el pueblo, y [...] volvemos con tanta insistencia sobre la necesidad de abrir nuevas y persistentes fuentes de recursos al Gobierno Nacional» ${ }^{37}$. El Estado debía proveer servicios y mejorar la situación de los sectores necesitados. De hecho, el Estado era conceptualizado como un motor activo para la modernización. Contra lo que - sostenían los liberales franceses más doctrinarios como Benjamin Constant, en una nota editorial se sostenía que el Congreso-, lejos de reflejar con la legislación las costumbres y los usos vigentes, debía cambiarlos activamente ${ }^{38}$. Sin embargo El Economista, como los otros periódicos analizados, hacía profesión de fe liberal, sosteniendo la existencia de un consenso indiscutible en este sentido. Así, por ejemplo, respecto de la cuestión religiosa, decía:

No habrá muchas otras naciones tan dividas en partidos o fracciones internas, a pesar de que todos sus ciudadanos se hallan perfectamente de acuerdo en cualquier cuestión de verdadera trascendencia: todos los argentinos quieren la libertad, todos son verdaderos liberales, aun los que sus creencias religiosas han inducido a afiliarse en el partido llamado "católico», que en otros países es considerado como enemigo implacable de la libertad política, mientras que entre nosotros uno puede muy bien pertenecer al partido clerical, sin por esto pasar por antiliberal ${ }^{39}$.

En temas vinculados a política monetaria El Economista, al igual que El Industrial, mostraba claras tendencias heterodoxas. Mientras los periódicos más vinculados al liberalismo clásico, tales como La Nación, El Plata Comercial y Agrícola ${ }^{40}$

${ }^{36}$ El Economista, V/III/13 (1 de abril de 1879): 154. Otra publicación de la época, El Plata Comercial y Agrícola, mantenía una postura similar a El Economista en este punto. Si bien se oponía abiertamente a la protección aduanera y reclamaba economías en los gastos públicos, sostenía a la vez que el Estado debía emprender medidas de aliento a la producción manufacturera, como los premios a las innovaciones que se repartían en Francia. El Plata, V/23 (20 de diciembre de 1877): 310. La revista era una publicación fundada por el doctor Mariano Varela, responsable de también de La Tribuna y ministro de Relaciones Exteriores y Culto durante la presidencia de Domingo F. Sarmiento. Era hermano de Rufino Varela, ministro de Hacienda del Presidente Juárez Celman y socio honorario del Club Industrial. Ambos eran hijos del periodista y escritor Florencio Varela.

37 El Economista, II/ I/22 (15 de noviembre de 1877).

38 El Economista, V/III/30 (8 de agosto de 1879).

39 El Economista, III/ II/ 17 (1 de mayo de 1878): 194.

40 El Plata Comercial y Agrícola sostenía: «La suspensión de pagos en metálico ha sido autorizada y el público ha visto en ella el cumplimiento de un hecho fatal contra el cual no era posible revelarse. No hay consideración, no hay ejemplo que nos haga mirar como un bien lo que reputamos una calamidad. Algunos han batido palmas, y han creído que la caída de la oficina de cambio era la conclusión de la crisis. No comprendemos como en esta población, donde tan reciente esta el recuerdo de los males que engendra el papel moneda, 
o La Libertad ${ }^{41}$ promovían el restablecimiento de la convertibilidad y el patrón monometalista oro eliminado en 1876, El Economista nuevamente tomaba una posición caracterizada como "práctica». Admitían que el patrón oro (asociado al librecambio) era la situación óptima a la cual había que tender necesariamente. Sin embargo, dada la situación del momento, un patrón plata (asociado al proteccionismo) podía ser una etapa de transición entre el papel y el oro ${ }^{42}$. Un articulista, miembro del Club Industrial, y posterior socio fundador de la Unión Industrial Argentina, Carlos Lix Klett, sostenía que debía lisa y llanamente desmonetizarse el metal y adoptar el papel como moneda, aunque dos páginas después del artículo una nota editorial dejaba en claro que la dirección del periódico, aunque respeta los profundos conocimientos del autor de la nota, discrepaba sobre la idea de desmonetización del metal ${ }^{43}$. Sin embargo, el hecho de que el artículo fuera publicado es significativo.

El Economista de alguna manera reflejaba el pensamiento de algunos sectores de la incipiente elite técnica estatal que, como se vio, estaba más vinculada a los intereses de los — también incipientes - industriales que a los de los ganaderos y agricultores. El contenido del periódico muestra las posibilidades y los límites de la autonomía de estos sectores respecto de las elites sociales y políticas, y al mismo tiempo pone de manifiesto la existencia de múltiples lógicas operando dentro del Estado en el proceso de modernización.

\section{La CRISIS DEL 90 y La ReNOVACión DEL CANON}

La crisis de 1890 representó un trauma mayor para la sociedad argentina. Tanto en el imaginario de sectores expertos como en aquel más vinculado al sentido común social, la experiencia del 90 devino en «la crisis», suerte de metro patrón que serviría de medida para caracterizar y evaluar todas las crisis posteriores, al menos hasta la década de 1930. En el ámbito de las ideas económicas y sociales, el 90 permitió un desplazamiento del piso de

donde todavía se sienten los trastornos en el orden económico que precedieron a la creación de esa oficina en 1867, ha podido nadie felicitarse ante su reciente clausura». El Plata, 1/ 3 (10 de junio de 1876): 25.

${ }^{41}$ La Libertad citaba a Adam Smith, pero sobre todo a Michel Chevalier para señalar las desgracias de uso del papel y la necesidad de volver lo antes posible al patrón oro. Ver, por ejemplo, La Libertad, 724 (29 de abril de 1876), «El marco de plata», nota en la que critican las propuestas de adoptar el patrón plata, y «La cuestión monetaria», La Libertad, 734 (11 de mayo de 1876).

42 El Economista, V/III/28 (24 de julio de 1879).

${ }^{43}$ Lix Klett, El Economista, I/I/ 11 (1 de junio de 1877). 
lo decible permitiendo (o más bien introduciendo) la posibilidad de cambios importantes de paradigmas como luego ocurriría en 1930. Si en las décadas anteriores aun las posiciones más heterodoxas y proteccionistas debían validarse o bien en su provisionalidad, o bien en la apelación a un canon de autoridades muchas veces vinculado a posturas contrarias a las que se sostenía, a partir del «momento 1890» la situación cambió rápidamente. Ahora parecía posible hacer referencias más explícitas a la Escuela Histórica Alemana y al socialismo de cátedra, tal como lo analizamos en otros trabajos ${ }^{44}$. A continuación nos detendremos en la Revista Económica del Río de la Plata.

Esta publicación es relevante porque las transformaciones que sufrió entre su primera época (1870-71) y su segunda época (a partir de 1892), a pesar de la continuidad de buena parte de sus colaboradores - incluyendo la presencia de Domingo Lamas, hijo del publicista uruguayo Andrés Lamas, primero como administrador y luego como director-, reflejan, de alguna manera, algunas transformaciones del liberalismo en la Argentina ${ }^{45}$. Aunque la publicación nunca renegó del liberalismo, las concepciones sobre el Estado y la economía cambiaron radicalmente entre la primera y la segunda época.

En su primera etapa, la revista (que contaba con Bartolomé Mitre entre sus colaboradores, junto con un gran número de italianos, incluyendo a su redactor, José Vattri, y Serafin Pollinini, fundador del Banco de Italia y del Río de la Plata y de la Cámara Italiana de Comercio de Buenos Aires) se declaraba liberal en sentido clásico. Su propósito era defender la libertad en su «triple manifestación: religiosa, civil y económica». La libertad, según los editores, iba asociada a la propiedad que, de manera Lockiana, era caracterizada como un derecho natural anterior al pacto social. En su primer número una nota editorial distinguía entre dos escuelas de pensamiento: una que promovía la «libre concurrencia y libre desarrollo del hombre moral e intelectual» — para lo cual se basan en la «sublime definición» del trabajo libre dada por Adam Smith; y otra que afirmaba que la solución a los problemas sociales y económicos estaba vinculada a un gobierno «que sea la concentración absoluta de todas las fuerzas individuales, sustituyendo el Estado, la sociedad colectiva, al

${ }^{44}$ Plotkin y Caravaca, en prensa, Plotkin y Caravaca, 21/2 (San Pablo, 2009).

45 Domingo Lamas había nacido en 1849 y desde muy joven se dedicó al periodismo. Fue diputado en el Uruguay y tuvo participación muy activa en la sanción de la ley de aduanas durante el gobierno de Santos. Escribió numerosos libros y estudios sobre temas económicos y bancarios, uno de ellos publicado originalmente en El Industrial. Instalado en la Argentina y siendo ministro de Hacienda José Terry le encargó estudios económicos. Fue director de la revista hasta 1919. Murió en 1925. Para un estudio clásico sobre los cambios del liberalismo en la Argentina, ver Zimmermann, 1995. 
propietario del capital particular». La primera escuela era caracterizada como de los «economistas» y la segunda como de «socialistas» ${ }^{46}$.

Desde el principio la RERP —en consonancia con los intereses de los banqueros italianos que formaban el grupo inicial de la revista - se opuso a la creación de un banco nacional con privilegios exclusivos, «atentatorio a la libertad y a la propiedad y factor, al mismo tiempo del unitarismo [...]». El gobierno no podía, en su visión, tener un banco sin violar la libertad de la industria ${ }^{47}$. La presencia de un banco estatal con capacidad de emisión aseguraría al Estado central ganancias por encima de la banca privada al poder imponer el curso forzoso. Sin embargo, este argumento de una impecable ortodoxia monetaria en contra del papel moneda se complementaba con otro de índole nacionalista. El proyecto de banco nacional mixto otorgaba demasiado poder a los socios ingleses.

La revista desapareció en marzo de 1871, menos de un año después de haber publicado su primer número. Más de veinte años más tarde, en mayo de 1892, reapareció. Según D. Lamas, la discontinuidad se debió a que Lucio V. Mansilla había fundado El Mercantil y lo había invitado a participar como redactor de la sección económica. Luego Lamas le devolvió el favor al invitar a Mansilla a dirigir la sección política de la revista renacida. Mansilla hizo pública su carta de contestación a la invitación de Lamas observando a este último que «estando Ud. conforme conmigo, cree que la base de la economía política está en la no intervención y que no hay reglamento que valga contra la ley de la oferta y la demanda ${ }^{48}$. Esta postura de Mansilla, quien se creía en la necesidad de hacerla explícita, como se verá iría a contrapelo de la orientación general de la revista.

Aunque la $R E R P$ seguía manteniendo su oposición explícita a cualquier forma de socialismo, su prédica no solo se volvió abiertamente proteccionista, sino también, y fundamentalmente, industrialista, en nombre de la independencia y el nacionalismo económico. El país debía basar su riqueza en la producción agrícola e industrial porque el comercio había dejado de ser ya la base del crecimiento y la prosperidad. Al igual que El Industrial años antes, la RERP proponía industrias que no solamente estuvieran destinadas a satisfacer el mercado interno, sino que también - siguiendo el modelo de los EE.UU.- - inundaran el mercado internacional. La industria azucarera,

46 Revista Económica del Río de la Plata (RERP en adelante), 1 (7 de agosto de 1870): 5.

47 RERP, 4 (28 de agosto de 1870). En el primer número de la segunda época, en una nota editorial, D. Lamas diría que fue gracias a la prédica de la revista que se aplazó el proyecto de banco nacional. RERP, $2^{\text {a }}$ época, 1 (1 de mayo de 1892): 2.

${ }^{48} R E R P, 2^{\mathrm{a}}$ época, 1 (1 de mayo de 1892): 21. 
despreciada por el Club Industrial en los años 70, pasó a ser un modelo a seguir ya que su tecnificación e inversiones le permitían exportar a pesar de la crisis. La novedad no solamente estaba en la discusión de algunos temas, sino también en la forma en que estos eran introducidos.

La reconceptualización de las relaciones entre Estado y sociedad y de las ideas básicas del liberalismo clásico aparecen formuladas con claridad en una nota editorial de Lamas de setiembre de 1892: «La sana doctrina consiste en que el individuo, que es la fuente del pensamiento y de la acción, debe tener, en la órbita de los intereses materiales, toda la libertad que se encuadra en los intereses generales y en la realización de los fines sociales. La salvaguardia y prosecución de estos fines e intereses no corresponden a la acción automática, pero sí vienen a constituir la del Estado ${ }^{49}$. Estos renovados espacios de intervención del Estado en la economía y la sociedad no debían limitarse al fomento de las actividades industriales a través del crédito y la protección, sino que debía extenderse hacia otras áreas mucho más amplias: «A la pregunta de si el Estado debe ser beneficente y a punto de constituir esto uno de sus deberes ineludibles, no vacilamos en contestar afirmativamente... Lo que es justicia y deber en la esfera de la familia no puede dejar de serlo para la comunidad nacional. El problema del seguro por el Estado y de las cajas oficiales destinadas a crear rentas para la vejez y para los casos de enfermedad y de accidentes surge del reconocimiento de esta verdad» ${ }^{50}$. Lo que se proponía eran las bases de un incipiente Estado social. De la misma manera, Lamas se opondría — con argumentos que simultáneamente apelaban a la eficacia económica y a la equidad social - a las liquidaciones en momento de crisis como los que vivía el país ${ }^{51}$.

Como decía Lamas - contradiciendo en esto a autores canónicos hasta hacía poco, tales como Joseph Garnier-: «Aquellos que se oponen a la acción estatal en nombre de la mayor eficacia de la acción individual no se dan cuenta de que esto no se consigue por medio de asociaciones anónimas». Lamas también revalorizaba el papel de la burocracia estatal en la que ya no veía la consecuencia de la empleomanía de abogados parasitarios desocupados. Pero mientras El Economista, como vimos, quince años antes bregaba por la conformación y valorización de una elite técnica estatal vinculada sobre todo a la producción de datos estadísticos, lo que proponía Lamas y otros desde las páginas de la $R E R P$ era una reconceptualización completa de la idea de funcionario público. Si en décadas anteriores los funcionarios del Estado eran

\footnotetext{
49 RERP, $2^{\mathrm{a}}$ época, (20 de septiembre de 1892): 256.

50 RERP, $2^{\text {a }}$ época, 18 (30 de enero de 1893): 459.

${ }^{51}$ Lamas, RERP, $2^{\mathrm{a}}$ época, 6 (20 de julio de 1892): 159.
} 
sospechosos de partidismo y empleomanía, ahora, en la visión de Lamas, constituían la garantía de eficiencia y transparencia.

Respecto de la política monetaria, la $R E R P$ en su segunda época, también se mostraba abiertamente heterodoxa. Mientras El Economista tres lustros antes se había visto forzado a distanciarse de las ideas osadas de uno de sus colaboradores en el sentido de desmonetizar la circulación del metal, la $R E R P$ no solamente se oponía a la valorización del papel frente al oro, sino que proponía un aumento de la emisión, ya que el aumento del circulante constituiría un elemento de expansión al generar una mayor demanda, mientras que la disminución del mismo atacaba no solamente a los precios, sino también al crédito y a la solvencia en general ${ }^{52}$. Yendo aún más allá, la revista proponía la implantación del curso forzoso con un valor del papel fijado por el Congreso. Esto llevaba a una disquisición sobre la naturaleza de la moneda que, según el articulista (probablemente Lamas) debía ser entendida como medio de cambio y por lo tanto no debía estar vinculada al valor material de la misma. En otro lado se dirá: «El billete no es una obligación de pago sino un medio de pago y un instrumento de cambio. Es dinero y no un título a dinero» ${ }^{53}$.

Si la $R E R P$ se pronunciaba en contra del patrón oro clásico era en parte porque esto le restaría autonomía monetaria al país. El problema de la dependencia de la Argentina respecto de potencias europeas, y en particular de Gran Bretaña, era un tema que ya había sido abordado desde la perspectiva industrialista por El Industrial. Sin embargo, ahora desde una perspectiva doctrinaria mucho más sofisticada, se esbozan argumentos que tendrían una resonancia en lo que muchas décadas después propondría Raúl Prebisch desde la CEPAL. Los ciclos económicos producidos en los «grandes centros de capital» son los que determinan, en última instancia, la circulación monetaria doméstica de los países nuevos según el sistema de patrón oro. Los países 'nuevos' «son provistos o empobrecidos de moneda de acuerdo con el movimiento discordante de los grandes centros de capital que se constituyen en desquiciadoras metrópolis y someten la vida económica de los países que les quedan subordinados a fuerzas tan ciegas como las que predominan en el estado natural» ${ }^{54}$.

52 RERP, $2^{\mathrm{a}}$ época, 4 (15 de junio de 1892): 93-94. Para sostener este punto citan a Émile Laveleye, quien dice que la rarificación del circulante implica una baja en los precios no producida por la abundancia de productos lo que genera una crisis lenta e insidiosa.

53 RERP, $2^{\mathrm{a}}$ época (25 de diciembre de 1892): 405.

${ }^{54} R E R P, 2^{a}$ época (20 de setiembre de 1892): 259-260. 


\section{Conclusiones}

Como se dijo en la introducción, el presente trabajo no tiene más pretensión que la de constituir un punto de partida para una investigación mucho más amplia. Sin embargo, podemos extraer algunas conclusiones tentativas. El análisis de las publicaciones periódicas especializadas del mundo económico e industrial en formación entre 1870 y 1890 — de lo cual el presente artículo es solo un primer paso-, constituye una vía de acceso a una serie de cuestiones más generales. Por un lado, permite penetrar en la construcción de formas de recepción de diversos sistemas de ideas. Estas publicaciones periódicas que circulaban por fuera de los circuitos de los «grandes diarios doctrinarios», y sin embargo dialogaban e interactuaban con ellos, conformaban verdaderas «correas de transmisión» de ideas. Los periódicos, que respondían a intereses particulares o especializados, permiten comprender como se procesaban cambios de paradigma dentro de grupos de interés específicos vinculados a sectores sociales y económicos determinados y/o a áreas de conocimiento singulares.

El análisis de estas publicaciones también nos proporciona una puerta de entrada oblicua - pero no por ello menos importante - para otros temas como, por ejemplo, el proceso de modernización del Estado. Los tres periódicos estudiados en este artículo permiten, desde lugares distintos, atisbar el complejo proceso de conformación de cuerpos profesionales técnicos estatales, sus alcances y limitaciones, así como la evolución de una cierta percepción sobre ellos. La imagen del Estado que emerge de ellos es sumamente matizada y es compatible con los hallazgos de investigaciones recientes realizadas desde otros puntos de vista $^{55}$. En efecto, las múltiples afiliaciones y la ubicuidad de los miembros del cuerpo técnico en formación que surge de cruzar los datos obtenidos de periódicos tales como El Industrial con El Economista durante la década de 1870 - y tenemos motivos para pensar que la situación no cambió radicalmente en la década siguiente_- sugieren un Estado repleto de «zonas grises» en el que sujetos individuales o colectivos que no pertenecían directamente a la esfera estatal cumplían funciones estatales en parte para suplir las incapacidades materiales —y simbólicas — , de este último. Es así como el Estado delegaba en los propios grupos autodefinidos como industriales la determinación del cobro de patentes; en ciertos periódicos la publicación de estadísticas «oficiales» — que en rigor de verdad solo una mirada muy optimista podría caracterizar como tales - y, en general, en los grupos interesados en la aplicación de legislación que los afectaba.

${ }_{55}$ Para un ejemplo de nuevas aproximaciones sobre la construcción del Estado en la Argentina, ver los trabajos incluidos en Plotkin y Zimmermann (eds.), 2012a y Plotkin y Zimmermann (eds.), 2012b. 
Así como Jorge Liernur mostraba tiempo atrás la existencia de una Buenos Aires «efímera» en la década de 1870, ubicada en un período de transición entre la Gran Aldea y la Ciudad Moderna, pero lejos aún de la imagen tradicional de gran metrópolis consolidada, y donde la característica saliente era la precariedad de las construcciones, la imagen de Estado que surge de estas publicaciones también ocupa un espacio semejante en el que la modernización y consolidación aparecen como procesos complejos, sumamente trabajosos, y en todo caso aun distantes, cuyos matices no han sido aún estudiados en profundidad ${ }^{56}$.

Las publicaciones analizadas también permiten acceder a otro tema que no ha sido suficientemente analizado en la Argentina, que es el desarrollo del liberalismo y sus matices durante la segunda mitad del siglo XIX. Esta problemática, que ha sido estudiada en profundidad en otros países latinoamericanos, no ha merecido una atención semejante en la Argentina, más allá de estudios clásicos y sin duda valiosos sobre las ideas de los «grandes hombres» ${ }^{57}$.

Finalmente, es de esperar que el análisis de estas y otras publicaciones semejantes en el futuro permitan obtener un panorama más completo del desarrollo de la prensa escrita y, en general, de la conformación de una esfera pública desde una perspectiva diferente, más periférica, respecto del punto de mira que habitualmente se toma como referencia.

\section{BIBLIOGRAFÍA}

«Abandono o protección. Falta de lógica», El Industrial, II/11 (1 de marzo de 1876). «Actas de la $12^{\circ}$ Asamblea general», El Industrial, II/ 30 (Buenos Aires, 15 de diciembre de 1876): 243.

Alonso, Paula, Entre la revolución y las urnas. Los orígenes de la Unión Cívica Radical y la política argentina en los años 90, Buenos Aires, Sudamericana, 2000.

Alonso, Paula, Jardines secretos, legitimaciones públicas. El Partido Autonomista Nacional y la Política argentina de fines del siglo XIX, Buenos Aires, Edhasa, 2010.

Boianovsky, Mauro, «Friedrich List and the Economic Fate of Tropical Countries» (April 15, 2011). History of Political Economy, 45/4 (Winter 2013). Disponible en: http://ssrn.com/abstract=1810846 or http://dx.doi.org/10.2139/ssrn.1810846.

56 Ver Liernur, 1993.

${ }^{57} \mathrm{La}$ literatura sobre el liberalismo latinoamericano es demasiado amplia para intentar siquiera un esbozo de reseña aquí. Una buena síntesis reciente puede encontrarse en Jaksic y Posada Carbó, 2011. Para la Argentina, una buena síntesis de trabajos recientes puede encontrarse en Roldán et al. 11/2005. Accesible en http://alhim.revues.org/index787.html. Ver también el texto ya clásico Halperin Donghi, 1988. 
Club Industrial, «La Aduana Nacional. Reformas solicitadas al Honorable Congreso de la Nación por el Club Industrial para el año 1879. Precedidas por un estudio teórico-práctico sobre la aplicación de un sistema proteccionista con relación a la producción de la República, escrito por Santiago Guzmán, Secretario de la Asociación», Buenos Aires, Imprenta de Pablo E. Coni, 1878.

«El Congreso y las cuestiones económicas», El Economista, III/II/17 (Buenos Aires, 1 de mayo de 1878): 194.

«El Club Industrial y el Centro Industrial», El Industrial, V/161 (Buenos Aires, 17 de enero de 1880): 1-2.

El Economista, I/I/3 (Buenos Aires, 15 de febrero de 1877).

El Economista, II/II/22 (Buenos Aires, 15 de noviembre de 1877).

El Economista, III/II/6 (Buenos Aires, 8 de febrero de 1878).

El Economista, V/III/13 (Buenos Aires, 1 de abril de 1879):154.

El Economista, V/III/17 (Buenos Aires, 1 de mayo de 1879).

El Economista, V/III/30 (Buenos Aires, 8 de agosto de 1879).

El Industrial, I/1 (Buenos Aires, 1 de octubre de 1875): 1.

El Industrial, I/3 (Buenos Aires, 1 de noviembre de 1875): 23.

El Industrial, III/45 (Buenos Aires, 2 de agosto de 1877): 393.

El Industrial, V/156 (Buenos Aires, 13 de diciembre de 1879).

El Industrial, V/185 (Buenos Aires, 17 de julio de 1880): 2.

«El libre cambio y proteccionismo. Nuestro credo y nuestros propósitos. A La Nación», El Industrial, III/50 (Buenos Aires, 15 de octubre de 1877).

«El marco de plata», La Libertad, 724 (Buenos Aires, 29 de abril de 1876).

«Exposición Industrial», El Industrial, III/33 (Buenos Aires, 1 de febrero de 1877): 264.

Fragueiro, Mariano, Cuestiones argentinas y organización del crédito, Buenos Aires, Solar/Hachette, 1976.

G. D., «Introductores e industriales», Boletín de la Unión Industrial Argentina, III/18, (Buenos Aires, 18 de septiembre de 1890): 1.

Halperin Donghi, Tulio, «Argentina: Liberalism in a Country Born Liberal», Joseph Love y Nils Jacobsen (eds.), Guiding the Invisible Hand. Economic Liberalism and the State in Latin American History, Nueva York, Praeger, 1988.

I. F., «La estadística comercial», La Industria, II/37 (Buenos Aires, 31 de octubre de 1880): $311-313$. 
Jaksic, Iván y Posada Carbó, Eduardo (eds.), Liberalismo y poder. Latinoamérica en el siglo XIX, Santiago de Chile, Fondo de Cultura Económica, 2011.

J. L. L., «La producción de la riqueza. El Contrabando intelectual en las Universidades. Las escuelas de artes, oficios y agronomía como único control», El Industrial, V/195 (Buenos Aires, 30 de octubre de 1880): 1-2.

J. L. L., «El Congreso y del Derecho Constitucional Argentino», El Industrial, V/226 (Buenos Aires, 4 de junio de 1881): 1-2.

J. L. L., «iToda la verdad pese a quien pese!,»El Industrial, 5/185 (Buenos Aires, 17 de julio de 1880): 2.

«La industrial argentina y los premios extranjeros», El Plata Comercial y Agrícola, V/23 (Buenos Aires, 20 de diciembre de 1877).

«La cuestión monetaria», La Libertad, 734 (Buenos Aires, 11 de mayo de 1876).

«La cuestión monetaria», La Libertad, V/III/30 (Buenos Aires, 8 de agosto de 1879).

«La situación monetaria. El Banco de la Provincia de Buenos Aires y el Banco Nacional», El Plata Comercial y Agrícola, 1/3 (Buenos Aires, 10 de junio de 1876): 25.

Lamas, Domingo, «Carta Económica», Revista Económica del Río de la Plata, 2a época, 6 (Buenos Aires, 20 de julio de 1892): 159.

Liernur, Jorge Francisco y Silvestri, Graciela El umbral de la metrópolis. Transformaciones técnicas y cultura en la modernización de Buenos Aires (1870-1930), Buenos Aires, Sudamericana, 1993.

Lix Klett, Carlos, «Las fluctuaciones del papel moneda», El Economista, 1/1/11 (Buenos Aires, 1 de junio de 1877).

Lomnitz-Adler, Claudio, «Times of Crisis. Historicity, Sacrifice, and the Spectacle of Debacle in Mexico City», Public Culture, 15/1 (2003): 127-147.

«Los empleados civiles», El Economista, I/I/12 (Buenos Aires, 15 de junio de 1877): 250.

«Nuestro Programa», El Economista, 1/1 (Buenos Aires, 18 de enero de 1877).

P. Y., «Las huelgas, sus causas y efectos», El Industrial, V/139 (Buenos Aires, 6 de agosto de 1879): 1190.

P. Y., «Las dos escuelas», El Industrial, III/104 (Buenos Aires, 2 de diciembre de 1878).

Plotkin, Mariano y Jimena Caravaca, «A economia entre crises: economia política e financas na Universidade de Buenos Aires (1870-1900)», Tempo Social, Revista de sociologia de UP, 21/ 2, (San Pablo, noviembre 2009).

Plotkin, Mariano Ben y Caravaca, Jimena «Las particularidades del liberalismo económico argentino. Circulación, adaptación y formación de un canon de pensamiento 
de economía política, 1870-1899», Ricardo González Leandri, Pilar González Bernardo de Quirós y Andrés Galera (eds.), Regulación Social, Regímenes de bienestar y Estado en América Latina: del liberalismo al neoliberalismo. Circulación internacional de saberes, actores e instituciones, Madrid, Editorial Polifemo, en prensa.

Plotkin, Mariano Ben y Eduardo Zimmermann (comps.), Los saberes del Estado, Buenos Aires, Edhasa, 2012a.

Plotkin, Mariano Ben y Eduardo Zimmermann (comps), Las prácticas del Estado. Política, sociedad y elites estatales en la Argentina del siglo XX, Buenos Aires, Edhasa, 2012b.

«Producción nacional, peligros que la amenazan», El Plata Comercial y Agrícola, 1/6 (Buenos Aires, 25 de julio de 1876).

«¿Qué nos conviene?», El Economista, V/III/28 (Buenos Aires, 24 de julio de 1879).

Revista Económica del Río de la Plata, 2a época, 4 (Buenos Aires, 15 de junio de 1892): 93-94.

Revista Económica del Río de la Plata, 2a época (Buenos Aires, 25 de diciembre de 1892): 405.

Revista Económica del Río de la Plata, 2a época (Buenos Aires, 20 de setiembre de 1892): 259-260.

Revista Económica del Río de la Plata, $2^{\mathrm{a}}$ época, 18 (Buenos Aires, 30 de enero de 1893): 459.

Revista Económica del Río de la Plata, 2a época (Buenos Aires, 20 de septiembre de 1892): 256.

Revista Económica del Río de la Plata, 1 (Buenos Aires, 7 de agosto de 1870): 5.

Revista Económica del Río de la Plata, 4 (Buenos Aires, 28 de agosto de 1870).

Revista Económica del Río de la Plata, 2a época, 1 (Buenos Aires, 1 de mayo de 1892): 2 .

Revista Económica del Río de la Plata, 2a época, 1 (Buenos Aires, 1 de mayo de 1892): 21.

Rosanvallon, Pierre, Le moment Guizot, París, Gallimard, 1985.

Roldan, Darío et al., «Amérique Latine Histoire et Mémoire». Les Cahiers ALHIM, 11(París, 2005). Accesible en http://alhim.revues.org/index787.html

Sidicaro, Ricardo, La política mirada desde arriba: las ideas del diario La Nación (1909-1989), Buenos Aires, Sudamericana, 1993. 
Tarcus, Horacio, Marx en Argentina. Sus primeros lectores obreros, intelectuales y cientificos, Buenos Aires, Siglo XXI, 2007.

«Tarifas de avalúos», El Industrial, V/156 (13 de diciembre de 1879).

Tato, María Inés, Viento de Fronda. Liberalismo, conservadurismo y democracia en la Argentina, 1911-1932, Buenos Aires, Siglo XXI, 2004.

Zimmermann, Eduardo, Los liberales reformistas. La cuestión social en la Argentina, 1890-1916, Buenos Aires, Sudamericana, 1995.

Fecha de recepción: 10/11/12

Fecha de aceptación: 21/1/13

\section{Specialized publications and peripheral liberalism. Notes on the circulation of economic ideas in Argentina, 1870-1890.}

This article - part of a larger project on the creation of «knowledge of state» in Argentina between the late nineteenth and 1930 - analyzes a series of publications that operated as «transmission belts» of economic knowledge and, more generally, of concepts tied to liberalism during the last decades of the n.ineteenth century in Argentina. What we want to reconstruct is the double process through which knowledge about the economy leads to an "expert discourse» socially recognized as such and, at the same time, certain ideas related to economy and society came to shape what could defined as an - always evolving - "social common sense».

Key words: Economics; Knowledge of State; Argentina; Periodicals. 